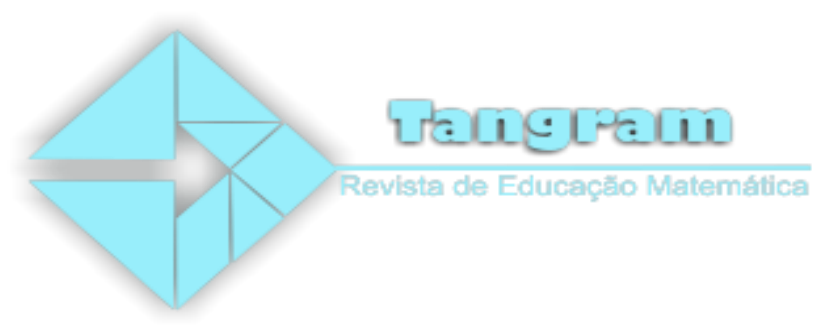

\title{
O papel das crenças e emoções no desenvolvimento da afetividade em relação à matemática nos anos iniciais do ensino fundamental
}

\author{
The participation of beliefs and emotions in the development of \\ affectivity in relation to mathematics in the initial years of elementary \\ school
}

\author{
Maria Cristina Otto ${ }^{1}$ \\ Fátima Aparecida Queiroz Dionizio ${ }^{2}$ \\ Celia Finck Brandt ${ }^{3}$
}

\begin{abstract}
Resumo: Esse artigo trata da relação entre a afetividade e o processo de ensino e aprendizagem de matemática nos anos iniciais do Ensino Fundamental, envolvendo crenças e emoções. Norteou-se pelo seguinte problema: Quais os fatores que influenciam na mobilização e no prazer que os alunos e professores têm ou deixam de ter pelo ensino e aprendizagem de matemática? Entre os autores que contribuem na fundamentação teórica dessa pesquisa estão Chacón (2003), Ponte (1992), Charlot (2000), Alves, Dantas e Oliveira (2012), Moura e Palma (2008), Silva (2008), Silveira (2012). A pesquisa foi realizada em uma escola pública de um município paranaense, com alunos de uma turma de $5^{\circ}$ ano do Ensino Fundamental e com oito professoras regentes de turma do $1^{\circ}$ ao $5^{\circ}$ ano. Evidenciou-se com essa pesquisa que há relação entre as crenças e concepções das professoras e as crenças dos estudantes no que se refere à matemática.
\end{abstract}

Palavras-chave: Afetividade. Matemática. Ensino e aprendizagem.

Abstract: This article is about relationships between Affectivity and the process of teaching and learning math in the early years of elementary school, involving beliefs and emotions. The problem addressed: What are the factors that influence to the mobilization and enjoyment that students and teachers have or do they neglect in the process of teaching and learning math? Contributed to the theoretical basis of this research, Chacón (2003), Ponte (1992), Charlot (2000), Alves, Dantas and Oliveira (2012), Moura and Palma (2008), Silva (2008), Silveira (2012). The research was carried out in a public school in a city of Paraná, with students of the 5th grade of Elementary School and with eight teachers from the 1 st to the 5 th grade. It was evidenced with this research that there is a

\footnotetext{
${ }^{1}$ Mestranda no Programa de Pós-Graduação em Ensino de Ciências e Educação Matemática da Universidade Estadual de Ponta Grossa. Licenciada em Pedagogia pela Universidade Estadual de Ponta Grossa (2017)

${ }^{2}$ Professora no curso de Pedagogia da UEPG e doutoranda em Educação pelo Programa de Pós-Graduação em Educação da mesma universidade. Licenciada em Matemática pela Universidade Estadual do Norte do Paraná (2008) e em Pedagogia pela Universidade Estadual de Ponta Grossa (2012). Especialista em Educação Matemática (2011) e Mestre em Educação pela UEPG (2013).

${ }^{3}$ Possui graduação em Licenciatura Em Matemática pela Universidade Federal do Paraná (1976), Mestrado em Educação pela Universidade Estadual de Ponta Grossa (1997) e doutorado em Educação Científica e Tecnológica pela Universidade Federal de Santa Catarina (2005). Atualmente é professora adjunta da Universidade Estadual de Ponta Grossa..
}

Tangram - Revista de Educação Matemática, Dourados - MS - v.2 n. 2, pp. 03-24 (2019) 


\section{O papel das crenças e emoções no desenvolvimento da afetividade em relação à matemática nos anos iniciais do ensino fundamental}

relation between the beliefs and conceptions of the teachers and the beliefs of the students in the teaching and learning in mathematics.

Keywords: Affectivity. Mathematics. Teaching and learning.

\section{Introdução}

A matemática é um tema no qual raramente não se têm uma opinião formada a respeito, é comum que muitos concebam essa disciplina como sendo extremamente complexa e ligada apenas aos aspectos cognitivos. Além do senso comum, existem também dados quantitativos ${ }^{4}$ que são considerados alarmantes em relação ao desempenho dos estudantes em matemática, em que grande parte dos estudantes não consegue aprender o considerado suficiente.

Os profissionais da educação e a população de modo geral podem buscar as respostas para o baixo rendimento na dimensão cognitiva, deixando de lado as questões afetivas que envolvem a construção do saber matemático. Porém, estudantes e professores ao adentrarem o ambiente escolar não são capazes de deixar suas emoções, crenças e sentimentos, pois a afetividade está presente no ser humano desde o seu nascimento até o fim da sua existência.

É comum nos depararmos na escola e em vários outros espaços, com indivíduos que sem hesitar, dizem não gostar de matemática. Essa constatação possibilita refletir sobre as peculiaridades do ensino da matemática e sobre o que pode ter feito ela se distanciar da apreciação das pessoas em geral. Então, é essencial analisar as práticas e as relações estabelecidas durante as aulas de matemática, considerando as dimensões afetiva e cognitiva de forma complementar para suprir as demandas durante o ensino e a aprendizagem nessa disciplina.

Analisar questões afetivas como crenças, emoções, sentimentos dos alunos e professores diante da matemática, pode contribuir para encontrar respostas relacionadas a outros problemas no ensino, como o fracasso escolar e o baixo rendimento dos alunos em matemática. Muitas experiências dos alunos nos anos iniciais do Ensino Fundamental seguirão com eles nos anos seguintes e, caso sejam muito negativas, podem contribuir para evasão escolar antes mesmo de chegarem aos anos finais do Ensino Fundamental. É preciso, então, buscar formas de melhorar e tornar o ensino da matemática mais bem quisto e mais prazeroso para os alunos e professores.

\footnotetext{
${ }^{4}$ QEdu. Disponível em: <http://www.qedu.org.br/>. Acesso em 06 jun. 2018.

Tangram - Revista de Educação Matemática, Dourados - MS - v. 2 n. 2, pp. 03 - 24 (2019)
} 


\section{O papel das crenças e emoções no desenvolvimento da afetividade em relação à matemática nos anos iniciais do ensino fundamental}

Desta forma, esta pesquisa busca resposta para o seguinte problema: Quais os fatores que influenciam na mobilização e no prazer que os alunos e professores têm ou deixam de ter pelo ensino e aprendizagem de matemática? A partir deste questionamento têm-se como objetivos: identificar os fatores que influenciam no gosto e mobilização de professores e alunos para o ensino e a aprendizagem de matemática e; evidenciar se as crenças e concepções dos professores podem interferir na crença, desejo e gosto pelo aprendizado dos alunos em matemática.

Para tanto, foi desenvolvida uma pesquisa exploratória, de abordagem qualitativa em uma escola municipal de uma cidade do Paraná. A pesquisa apresentada neste artigo referese a uma parcela do conhecimento construído durante a elaboração de uma monografia para conclusão do curso de Licenciatura em Pedagogia. Para a obtenção dos dados foram utilizados como instrumentos entrevistas, que foram realizadas com 8 professoras regentes das turmas de $1^{\circ}$ ao $5^{\circ}$ dos anos iniciais do Ensino Fundamental e questionários para 27 alunos do $5^{\circ}$ ano do Ensino Fundamental. A escolha da turma do $5^{\circ}$ ano para serem aplicados os questionários, se deu levando em conta a maturidade dos estudantes para responderem as questões elaboradas. Os estudantes e os professores foram identificados por nomes fictícios nessa pesquisa, para preservar suas identidades.

Para a discussão, análise e reflexão sobre os dados obtidos durante a pesquisa serão primeiramente exploradas as respostas dos professores para as entrevistas e posteriormente, as dos alunos para os questionários. A apresentação desta análise neste artigo será estruturada com base nas questões propostas, com a intenção de identificar possíveis relações entre as crenças e emoções dos professores e dos alunos com o saber matemático. Ao final serão destacados pontos em comum entre os dados adquiridos com os alunos e com as professoras.

\section{Relações entre crenças e emoções sobre o ensino e aprendizagem de matemática por professores e estudantes}

Entre os autores que contribuem na fundamentação teórica dessa pesquisa estão Chacón (2003), Ponte (1992), Charlot (2000), Alves, Dantas e Oliveira (2012), Moura e Palma (2008), Silveira (2012). Partindo de um conceito mais amplo de domínio afetivo, Chacón (2003) faz a classificação dos diferentes tipos de crenças e as diferentes emoções

Tangram - Revista de Educação Matemática, Dourados - MS - v.2 n. 2, pp. 03 - 24 (2019) 


\section{O papel das crenças e emoções no desenvolvimento da afetividade em relação à matemática nos anos iniciais do ensino fundamental}

que podem envolver o ensino e aprendizagem de matemática. Ponte (1992) contribui com o estudo das concepções docentes sobre a matemática e sua importância na construção da concepção dos estudantes e Charlot (2000) com os estudos sobre a relação com o saber. Alves, Dantas e Oliveira (2012) ao considerarem durante o processo de ensino e aprendizagem, o sujeito em sua integralidade, a partir das dimensões afetiva, cognitiva e motora. Moura e Palma (2008) com a ênfase nas lembranças de estudantes de pedagogia sobre os materiais didáticos usados durante as aulas de matemática e Silveira (2012), a partir do sentido pré-construído sobre a matemática e a influência das diferentes esferas da sociedade.

No decorrer da pesquisa foi possível relacionar questões respondidas pelos professores e pelos estudantes, possibilitando uma visão mais ampla das relações estabelecidas durante o processo de ensino e aprendizagem de matemática dentro da escola. Optou-se por trabalhar com a articulação das respostas obtidas nas entrevistas e nos questionários por proporcionar análise e reflexão mais ricas das questões levantadas.

Antes de abordar as questões propostas nos instrumentos de coleta de dados, é importante pontuar alguns elementos teóricos. Sobre as definições de domínio afetivo, podemos constatar que existem várias, cada uma segundo a perspectiva e estudos de cada autor. A definição que vem sendo mais usada, segundo Chacón (2013, p.20), é a que afirma que "O domínio afetivo inclui atitudes, crenças, considerações, gostos e preferências, emoções, sentimentos e valores".

É importante pontuar também, que foco do ensino e da aprendizagem em matemática muitas vezes está no cognitivo e no ato de raciocinar logicamente para que consigam resolver as situações propostas em sala de aula. Nesses casos, a dimensão afetiva geralmente é ignorada ou considerada como sendo algo negativo ou nulo durante o processo de ensino e aprendizagem. Diariamente os docentes tentam superar os desafios em sala de aula, buscando descobrir as causas para as dificuldades de seus alunos em matemática e as respostas podem estar justamente nas dimensões afetivas, como por exemplo, nas crenças dos alunos, nas emoções, nos sentimentos e em suas atitudes em relação à matemática.

O ensino e a aprendizagem em matemática envolvem diversos sujeitos que estão em relação com um determinado contexto social. Então o aluno não depende apenas dele para conseguir aprender, além de suas crenças, sentimentos e emoções, existem ao seu redor os afetos de seus pais, dos seus colegas, dos seus professores, entre outros. As crenças, 


\section{O papel das crenças e emoções no desenvolvimento da afetividade em relação à matemática nos anos iniciais do ensino fundamental}

principalmente dos professores diante da matemática, podem ser determinantes nas crenças dos educandos sobre a mesma. O estudo sobre a afetividade permite refletir sobre experiências que os professores e alunos têm ou tiveram em relação à matemática e, pode então, contribuir para que se avaliem indiretamente as práticas que estão acontecendo no contexto escolar.

Sendo assim, as questões dos questionários e entrevistas escolhidas para compor esse artigo foram selecionadas conforme as suas relações com os problemas e objetivos de pesquisa elencados. A construção dos instrumentos de pesquisa aconteceu de maneira que fosse possível perceber determinadas questões que envolvem o processo de ensino e aprendizagem de matemática do ponto de vista dos professores e dos alunos e a influência mútua entre as suas crenças, sem descartar o quão determinante é também o contexto histórico social dos sujeitos e os outros grupos sociais que convivem. O roteiro de entrevista com os professores elaborado para a monografia que deu origem a este artigo continha 12 perguntas, das quais, 10 foram escolhidas para serem apresentadas neste artigo. As questões propostas para as professoras durante as entrevistas e escolhidas para este artigo foram as seguintes:

a) Na sua trajetória escolar cite duas lembranças relacionadas às aulas de matemática nos anos iniciais do fundamental.

b) Qual sentimento que você tem relação à matemática?

c) Ao concluir sua formação inicial para a ação docente, se sentiu preparado para o ensino da matemática nos anos iniciais do fundamental? Por quê?

d) Os alunos que apresentam dificuldade de aprendizagem na matemática também apresentam dificuldade em outras disciplinas?

e) Em sua opinião, o que diferencia a matemática de outras disciplinas?

f) Das disciplinas citadas abaixo enumere de 1 a 5 as matérias que considera mais fácil ensinar, sendo 1 a mais fácil e 5 a mais difícil."

g) Para você o que mais influencia na aprendizagem dos alunos em matemática?

h) Quais são as maiores dificuldades dos alunos no aprendizado de matemática?

i) Em que os alunos têm mais facilidade no aprendizado de matemática?

j) Para você professor por que é importante ensinar matemática?

Tangram - Revista de Educação Matemática, Dourados - MS - v.2 n. 2, pp. 03 - 24 (2019) 


\section{O papel das crenças e emoções no desenvolvimento da afetividade em relação à matemática nos anos iniciais do ensino fundamental}

Durante a entrevista realizada com as professoras regentes de turma da escola para o item "a) Na sua trajetória escolar cite duas lembranças relacionadas às aulas de matemática nos anos iniciais do fundamental", pode-se perceber nas respostas para esta questão que as lembranças dos professores se referem à matemática com uma aprendizagem de uma forma mecânica, onde se priorizava a memorização e as técnicas (ensino clássico).

Durante os relatos foram marcados também componentes afetivos, como medo e gosto; relação professor e aluno e relação dos alunos com o conteúdo. Uma resposta que pode exemplificar esse aspecto é a resposta da professora Daiana que afirmou " [...] quando eu estava na segunda série, a professora sempre mandava a gente no quadro resolver as contas, que ela sempre corrigia no quadro e eu não soube fazer e naquela época a professora podia "xingar" para valer, na minha época era mais tradicional o ensino, a professora que era a líder da sala, ela que ensinava, ela ameaçou me bater e nisso eu fiz "xixi" na calça e isso me marcou muito no segundo ano." Segundo Moura e Palma (2008) os conceitos sobre a matemática são construídos historicamente, e dessa forma as lembranças também vão se transformando a partir das experiências dos sujeitos com esse conhecimento em cada época. Aspecto esse que fica evidente nas respostas apresentadas.

A lembrança negativa e de grande impacto da professora Daiana, pode ter contribuído para a construção de suas crenças sobre o ensino e aprendizagem de matemática, porém ao longo do tempo também sofreu influências de outros grupos de convivência e das experiências que teve com o saber matemático. São também determinantes as vivências da professora como docente, onde agora se ocupa o papel de quem a marcou intensamente na relação que estabelecia com a matemática em sua infância, mas agora se tornando agora capaz de contribuir na construção de boas lembranças dos seus alunos sobre o ensino e aprendizado de matemática.

Quando observamos a fala da professora Celina "No primeiro ano do ensino médio aprendi a gostar de matemática com o professor Carlos, ele não usava material didático, ele ia para sala com o livro de chamada e o material dele, o livro didático dele e ele passava no quadro e explicava e eu entendia sabe", podemos relacionar com estudos de Moura e Palma (2008) sobre as lembranças dos sujeitos ligadas ao material didático usado nas aulas, evidenciando que se deve buscar construir com os alunos motivos eficazes para aprender matemática e para que o ensino e a aprendizagem se tornem mais atrativo e significativo. $\mathrm{Na}$ fala da professora Celina, é possível perceber que mesmo que o professor não tenha Tangram - Revista de Educação Matemática, Dourados - MS - v.2 n. 2, pp. 03 - 24 (2019) 


\section{O papel das crenças e emoções no desenvolvimento da afetividade em relação à matemática nos anos iniciais do ensino fundamental}

utilizando uma variedade de materiais didáticos, os materiais que ele utilizou marcou sua formação, fazendo com que ela passasse a gostar da matemática. Porém, os materiais didáticos e os métodos não são suficientes para que isso se efetive e que devem ser usados de forma complementar, pois o significado é algo vivo construído na relação entre os sujeitos.

No item “b) Qual sentimento que você tem relação à matemática?”, as respostas dos professores foram agrupadas conforme os elementos que se sobressaíram, 3 professores escolheram o gosto (prazer), 1 amor, 1 medo, 1 paixão, 1 tranquilidade e 1 amor e ódio.

Com essa pergunta observou-se certa dificuldade das professoras em definir sentimentos, o que não significa que não exista a emoção, mas reflete sim a dificuldade das pessoas para definir o estado emocional. Isso reforça o que Chacón (2003) evidencia ao ressaltar a necessidade de uma alfabetização emocional, para que os sujeitos tenham clareza sobre seus sentimentos e possam desenvolver habilidades que lhes possibilite isso. Mesmo com experiências negativas relatadas em suas lembranças, conforme foi possível observar nas respostas para o item a, os sentimentos que prevaleceram foram os positivos, sendo o gosto (prazer) como o mais recorrente entre as professoras. A professora Suzana afirmou sentir "Amor e ódio, quando eu era criança de ódio, mas por questão de não saberem trabalhar matemática comigo. Hoje de amor por causa dos meus alunos, eu tento não transferir isso para eles, fazer da matemática algo mais gostoso". Ela menciona que tem dois sentimentos opostos em relação à matemática e ao dizer que tenta não transferir sua frustração com a matemática em sua época de estudante, demonstra que esta consciente de que as sua crenças e sentimentos em relação à matemática podem ajudar a compor as crenças e sentimentos dos estudantes sobre o ensino e aprendizado de matemática.

No item “c) Ao concluir sua formação inicial para a ação docente, se sentiu preparado para o ensino da matemática nos anos iniciais do fundamental? Por quê?”. Dentre as 8 professoras 6 afirmaram que não sentiram preparadas e 2 que sim.

Podemos observar nas respostas dos professores que esteve muito evidente a falta da articulação entre a teoria e a prática, isso pode ser observado na resposta da professora Suzana que afirma que não se sentiu preparada após a formação inicial por ser "Pouca prática e muita teoria" e também na resposta da professora Celina que justifica a falta de preparação pela "Importância do magistério e a falta de prática na Pedagogia”. Esse aspecto pode estar relacionado ao que Silva (2008) ressalta ao dizer que a construção do Tangram - Revista de Educação Matemática, Dourados - MS - v.2 n. 2, pp. 03 - 24 (2019) 


\section{O papel das crenças e emoções no desenvolvimento da afetividade em relação à matemática nos anos iniciais do ensino fundamental}

saber também se articula aos saberes da instituição que o indivíduo pertence. Nesse caso, seria a relação dos professores enquanto ainda estavam no processo de formação, ou seja, estabeleciam uma relação com o conhecimento como alunos de uma instituição. Porém, esta instituição pode não ter possibilitado a construção de saberes matemáticos de forma significativa aos futuros professores.

Também é possível perceber com estas respostas que os professores apontam o curso de magistério, que seria a formação em nível médio, como sendo importante para o ensino de matemática, isso se deve ao fato do magistério ser um curso técnico para formar professores e também onde muitas vezes se prioriza a técnica e o saber fazer, que costuma ser um aspecto valorizado pelos professores que estão atuando. Segundo Silva (2008) cada instituição mantém relações próprias com os saberes, então quando os sujeitos fazem parte de determinada instituição para poder apreender os saberes transpostos por ela deve entrar na peculiar relação que a instituição estabelece com os conhecimentos. Outro impasse que ficou visível e se repetiu nas respostas dos docentes foi a mudança nas formas de ensinar, destacando-se a necessidade contínua de se atualizar diante dos conhecimentos matemáticos.

No item “d) Os alunos que apresentam dificuldade de aprendizagem na matemática também apresentam dificuldade em outras disciplinas?", as respostas de 7 professores, foi de que os alunos apresentam sim essa dificuldade e a disciplina indicada por eles foi a de Língua Portuguesa. Talvez isso ocorra pelo fato dessas professoras serem responsáveis apenas pelo trabalho com estas duas disciplinas. As demais disciplinas são ministradas por outras professoras.

Chamou a atenção o fato de apenas uma professora afirmar que não tem alunos com dificuldade de aprendizagem, porém ao explicar como ela percebe este aspecto, a professora Celina ressalta que "Não apresentam grande dificuldade nem em português nem em matemática, tem aqueles que o processo é mais lento, que tem dificuldade, mas se vocêfizer um trabalho mais individualizado eles vão aprender". Ou seja, esta professora expressa o entendimento de que a dificuldade de aprendizagem pode ser algo temporário e que tende a ser superada por meio de um trabalho mais específico junto ao aluno. Embora possa não ser consciente, o que esta professora aponta relaciona-se com as ideias de Charlot (2000), quando ele afirma que não há fracasso escolar, na verdade há alunos em situação de fracasso, e que pode ser superada. Segundo o autor o fracasso escolar não deve ser pensado como se

Tangram - Revista de Educação Matemática, Dourados - MS - v.2 n. 2, pp. 03 - 24 (2019) 


\section{O papel das crenças e emoções no desenvolvimento da afetividade em relação à matemática nos anos iniciais do ensino fundamental}

fosse uma "coisa" ou até mesmo como uma enfermidade, mas sim como um fenômeno composto por diversas variáveis, Charlot (2000, p. 16) afirma que:

Existem, é claro, alunos que não conseguem acompanhar o ensino que lhes é dispensado, que não adquirem os saberes que supostamente deveriam adquirir, que não constroem certas competências, que não são orientados para a habilitação que desejariam, alunos que naufragam e reagem com condutas de retração, desordem, agressão. É o conjunto desses fenômenos, observáveis, comprovados, que a opinião, a mídia, os docentes agrupam sob o nome de "fracasso escolar".

Ao pensar em fracasso escolar é comum os profissionais da educação ignorem o que existe por trás desse fenômeno, ele não é algo que se desenvolve isoladamente e independente do contexto social no qual os sujeitos estão inseridos e suas vivências. Por isso Charlot (2000, p.16) afirma que esse fenômeno, assim pensado não existe, e que:

O fracasso escolar não é um monstro escondido no fundo das escolas e se joga sobre as crianças mais frágeis, um monstro que a pesquisa deveria desemboscar, domesticar, abater. O "fracasso escolar" não existe; o que existe são alunos fracassados, situações de fracasso, histórias escolares que terminam mal. Esses alunos, essas situações, essas histórias é que devem ser analisados, e não algum objeto misterioso, ou algum vírus resistente, chamado "fracasso escolar".

No item “e) Em sua opinião, o que diferencia a matemática de outras disciplinas?”, a maioria das professoras respondeu que o que distingue a matemática de outras disciplinas é o fato dela ser exata e estática. Essas respostas podem ser o resultado das experiências que os sujeitos tiveram durante sua trajetória escolar em matemática que foram exploradas no item a da entrevista referente às lembranças dos professores nos anos iniciais do Ensino Fundamental.

Esse aspecto está visível nas respostas da professora Margarete que afirma que "Ela diferencia por ser exata, você sabe que você resolve ali e não tem mais que ficar procurando outras respostas para aquilo, é aquela resposta e pronto[...]” e da professora Suzana que responde que "A matemática é exata né, aquilo você tem o processo e é exata se você foge daquele processo vai dar errado, diferente de português é mais complicado, eu gosto, mas é mais complicado, você vai corrigir um texto você tem que entender, porque ele escreveu aquilo, o pensamento dele."

Segundo Chacón (2003) o professor que tem a concepção em que a matemática é considerava estática, considera a matemática um conjunto de conhecimentos único e imóvel, Tangram - Revista de Educação Matemática, Dourados - MS - v.2 n. 2, pp. 03 - 24 (2019) 


\section{O papel das crenças e emoções no desenvolvimento da afetividade em relação à matemática nos anos iniciais do ensino fundamental}

então, nada de novo nasce na matemática, tudo já existe e só pode ser descoberto e não criado. E como a autora ressalta, a forma de conceber a matemática irá influenciar também nas práticas dos docentes e as crenças dos estudantes sobre a essa disciplina. Esse aspecto também é corroborado por Ponte (1992) quando ressalta o importante papel do professor na construção da concepção dos alunos sobre a matemática, pois a partir de sua prática e das relações que estabelece com os alunos é capaz de proporcionar diversas experiências dos alunos com a matemática em sala de aula.

Fica visível também na fala das professoras que o foco está no uso do concreto colaborando para a construção de conhecimentos matemáticos. Está ausente nos discursos das professoras, a importância do desenvolvimento do pensamento abstrato na matemática, isso fica claro na resposta da professora Priscila “A matemática é a parte mais lúdica, tudo você pode colocar no lúdico, todas as disciplinas você pode colocar no lúdico, mas a matemática tem uma força a mais do lúdico, tudo você pode apresentar ela no concreto, não existe a matemática fora do concreto." Em certo momento é necessário que o aluno se desprenda do concreto e que seja capaz de pensar e solucionar os problemas sem a necessidade de existir algo palpável, desenvolvendo a habilidade de cálculo mental.

Chamou à atenção a resposta de Margarete que considera os conhecimentos matemáticos como sendo mais necessários do que alguns conhecimentos da área da geografia e da história. Apenas a professora Priscila ressaltou a matemática podendo ser trabalhada mais no lúdico do que outras disciplinas e, além disso, enfatiza que não existe matemática sem o concreto. Isso pode ter sido ocasionado pelo menor número de aulas das disciplinas de história e geografia nos anos iniciais do Ensino Fundamental e pela dificuldade em visualizar a utilização dessas disciplinas na "prática" e no cotidiano, havendo uma visão menos utilitarista e instrumental delas.

No item "f) Das disciplinas citadas abaixo enumere de 1 a 5 as matérias que considera mais fácil ensinar, sendo 1 a mais fácil e 5 a mais difícil." As disciplinas para colocar o nível de facilidade eram Português, Matemática, História, Geografia e Ciências. Para esse item 3 professores assinalaram a matemática como sendo a mais fácil de ensinar ( $1^{\circ}$ posição), 3 como a mais difícil ( $5^{\circ}$ posição), e 2 sendo a penúltima disciplina mais difícil (4º posição).

As respostas nos mostram que os professores consideram a facilidade de ensinar a matemática em dois polos distintos, pois 3 professores indicam que esta é a disciplina mais fácil de ensinar e na mesma quantidade os professores à apontam como a mais difícil. As

Tangram - Revista de Educação Matemática, Dourados - MS - v.2 n. 2, pp. 03 - 24 (2019) 


\section{O papel das crenças e emoções no desenvolvimento da afetividade em relação à matemática nos anos iniciais do ensino fundamental}

posições 2 e 3 não apareceram nas respostas, o que reflete que não há uma consideração intermediária a esse respeito. De acordo com Silveira (2012), o discurso que afirma que a matemática é difícil, nesse caso, confirmando o nível de facilidade em última posição tem um sentido pré-construído, quando os sujeitos dizem que a matemática é difícil, mesmo que de forma não consciente acaba por admitir que a matemática é para poucos, reproduzindo o que geralmente é manifestado pela escola e mídia.

Esse sentido pré-construído é fortalecido pelos fatos históricos sobre o ensino da matemática, que em diversos períodos excluiu muitos do acesso aos conhecimentos matemáticos, o que acaba por reforçar o sentido que não é qualquer um que aprende matemática. Acompanhado desse sentido também existe o discurso no qual não é qualquer um que pode ensinar matemática, e quem ensina essa disciplina considerada difícil adquire um status que é para poucos. (SILVEIRA, 2012).

No item "g) Para você, o que mais influencia na aprendizagem dos alunos em matemática?". Nessa questão os professores tinham as seguintes opções de resposta: Formação do professor (desde o ensino básico até o superior); metodologia usada durante a aula; vontade de aprender dos alunos, apoio da equipe gestora da escola para o professor; experiências do aluno fora e dentro da escola com a matemática; diversidade de materiais didáticos; tempo. Eles poderiam escolher apenas uma opção.

A maioria dos professores elencou que a metodologia usada durante a aula como é o que mais influencia no aprendizado dos alunos, o que elucida a grande importância atribuída ao método e reflete nas emoções (afetividade). Isso pode ter sido desencadeado pelo fato da maioria dos professores valorizarem o saber fazer, como ficou explicito nas respostas do item c. A metodologia usada durante a aula é importante sim para o aprendizado dos alunos, mas não deve ser a única base para um ensino e aprendizagem significativa. Deve estar ligada a outros fatores, como as relações estabelecidas tanto com o saber matemático, quanto com os sujeitos e com o mundo que cerca os estudantes, conforme afirma Charlot (2000).

No item "h) Quais são as maiores dificuldades dos alunos no aprendizado de matemática?" As dificuldades citadas pelas professoras foram:

- Compreensão de trocas, operações e emprestar;

- Subtração de emprestar;

- Interpretação de soluções problemas;

- Identificar e reconhecer o número;

Tangram - Revista de Educação Matemática, Dourados - MS - v.2 n. 2, pp. 03 - 24 (2019) 


\section{O papel das crenças e emoções no desenvolvimento da afetividade em relação à matemática nos anos iniciais do ensino fundamental}

- Nomenclatura;

- Sequência numérica e paralelo tabuada/soma;

- Pensamento abstrato, quantificar e conceitos básicos;

- Atenção.

Foi observado nesse item que o grande foco dos docentes está nos conteúdos, e não nas subjetividades dos alunos, na relação professor/educando, nem em suas diferentes formas de aprender. A única resposta que saiu dessa linha foi a que se referia a falta de atenção como uma das dificuldades dos alunos, essa resposta pode estar ligada a crença na qual se acredita que para aprender precisa-se estar em silêncio, deixando de lado a importância do diálogo.

Em um ambiente de sala de aula os professores estão lidando com expectativas de diferentes indivíduos e ao pensarmos nesse aspecto não podemos descartar o papel das crenças nesse contexto. Segundo Chacón (2003) os estudantes têm suas expectativas sobre como se desenvolverá o ensino da matemática e quando essas expectativas são rompidas e as crenças dos alunos não se exteriorizam os alunos sentem-se desmotivados e não vem sentido no aprendizado. Então as crenças e concepções dos professores sobre a matemática são decisivas para que os alunos se mobilizem para o ensino e aprendizagem sobre ela, pois elas tendem a condicionar sua prática em sala de aula.

Ponte (1992, p.20) destaca cinco orientações sobre as concepções pedagógicas no ensino aprendizagem de matemática, as "centradas no conteúdo com ênfase na compreensão conceptual", as "centradas no conteúdo, com ênfase na execução", as "centradas no aluno", as "centradas na organização da sala de aula" e as "centradas no conteúdo, com ênfase nas situações problemáticas". As concepções e as práticas dos professores sofrem influências do contexto social, do clima político e da necessidade de conhecimentos operacionais, afirma Ponte (1992), portanto não deve ser analisada de forma isolada.

No item “i) Em que os alunos têm mais facilidade no aprendizado de matemática?" As facilidades dos alunos citadas pelos professores foram:

- Tabuada, compreender o processo;

- Multiplicação;

- Sequência numérica e operações;

- Contagem;

- Uso do concreto;

Tangram - Revista de Educação Matemática, Dourados - MS - v.2 n. 2, pp. 03 - 24 (2019) 


\section{O papel das crenças e emoções no desenvolvimento da afetividade em relação à matemática nos anos iniciais do ensino fundamental}

- Uso de jogos e brincadeiras;

- Uso do lúdico, com dados gráficos e comparações;

- Ao realizar um trabalho individualizado.

Nesse item os professores apontam o que os alunos têm mais facilidade na matemática e a maioria ainda destaca os conteúdos, porém surgem elementos novos, como a ludicidade, jogos e brincadeiras e o uso do concreto. Três professoras indicam procedimentos/estratégias de ensino e não apenas conteúdos, como ocorreu na questão anterior. Essa mudança expressa o que pode ser resultado das crenças e concepções dos docentes relacionados à aprendizagem de seus alunos em matemáticas. Suas experiências com a ludicidade durante sua vida profissional ou na sua formação podem contribuir para construção dessas crenças e ou concepções, nas quais se acredita que os conhecimentos matemáticos são construídos com mais facilidade quando se aprende brincando, por exemplo, e isso tende a refletir na sua prática, ocasionando a valorização dessas estratégias em sala de aula, como já antes mencionado com base no que afirmam Ponte (1992) e Chacón (2003).

A matemática pode ser considerada uma disciplina pouco flexível, e isso pode muitas vezes bloquear os estudantes e o uso do lúdico pode ser uma alternativa viável para que possam ser amenizados sentimentos negativos e serem aproveitados os sentimentos positivos, Kishimoto (1998, p.140) afirma que "A conduta lúdica oferece oportunidades para experimentar comportamentos que, em situações normais, jamais seriam tentados pelo medo do erro e da punição". Esse é um primeiro passo que para a variação das estratégias em sala, onde professores começam a enxergar que os educandos aprendem mais quando usam jogos, brincadeiras, o faz de conta, a imaginação, entre outros. Também aparece nas respostas o ensino individualizado como algo que facilita o aprendizado, isso descontrói a ideia de um único ensino para todos, é necessário a partir dessa perspectiva, ensinar a todos e cada um.

No item “j) Para você professor por que é importante ensinar matemática?” A maioria dos professores destaca a importância de ensinar a matemática para ser usada cotidiano dos sujeitos e na vida de uma forma geral. Isso evidencia uma articulação dessa disciplina com a vida, se observa uma visão predominantemente utilitarista (troco, valor do dinheiro) da matemática, pode também significar que está em segundo plano a importância do seu ensino para o desenvolvimento intelectual e para a construção de conhecimentos. Chacón (2003) identifica esse tipo de visão como a que considera a matemática como uma "caixa de Tangram - Revista de Educação Matemática, Dourados - MS - v.2 n. 2, pp. 03 - 24 (2019) 


\section{O papel das crenças e emoções no desenvolvimento da afetividade em relação à matemática nos anos iniciais do ensino fundamental}

ferramentas" que está guiada pelos objetivos externos que se deseja alcançar, e as aulas do professor que adota essa visão tende a propor um ensino onde existe a valorização das regras e procedimentos.

Segundo Chacón (2003) a matemática é uma ciência, mas não deve ser pensada apenas por esse aspecto, além disso, devemos considerá-la como parte do cotidiano e como uma atividade humana, contudo precisa fazer sentido aos sujeitos, englobando a realidade das pessoas e não se tornar apenas um conteúdo vazio transmitido nas escolas. Nas respostas das professoras ficou evidente que o uso da matemática no cotidiano, para a vida, para o futuro, entre outras estão presentes em seus discursos, porém esse não é o único aspecto que deve ser ressaltado quando pensamos em seu ensino e aprendizagem, Abrantes (1986, p.83) citado por Ponte (1992, p. 22) afirma que:

[...] os futuros professores valorizam as finalidades que se referem à aquisição de conhecimentos de Matemática necessários à continuação dos estudos, a outras disciplinas ou a situações rotineiras, mas atribuem pouca importância às finalidades associadas a um papel activo e criador dos alunos na aprendizagem da Matemática.

Dentre as respostas dos professores se destaca a resposta da professora Priscila, que se sobressai da visão utilitarista da matemática, ao evidenciá-la como sendo importante para o convívio social. A fala da professora vai ao encontro do que Alves, Dantas e Oliveira (2012) defendem quando afirmam que é preciso considerar as pessoas em suas dimensões afetivas, intelectuais, corporais, sexuais e sociais. Durante o processo de ensino e aprendizagem é necessário considerar todos esses aspectos, pois a escola exerce um papel social e visa preparar as pessoas para o mundo e para as relações sociais, todos os conhecimentos estão envolvidos por relações entre os sujeitos e são historicamente construídos, inclusive os saberes matemáticos.

As perguntas apresentadas para os alunos, assim como as dos professores, compartilham os mesmos objetivos e problemas de pesquisa. Do questionário elaborado para a monografia que deu origem a este artigo para os alunos, contendo 10 questões, foram selecionadas 6 delas que apresentam relação mais próxima com as questões dos professores:

a) Das disciplinas citadas abaixo enumere de 1 a 5 as matérias que mais gosta, sendo 1 a que mais gosta e 5 a que menos gosta.

b) Quando pensa na disciplina de matemática qual é a primeira coisa que vem a sua mente?

Tangram - Revista de Educação Matemática, Dourados - MS - v.2 n. 2, pp. 03 - 24 (2019) 


\section{O papel das crenças e emoções no desenvolvimento da afetividade em relação à matemática nos anos iniciais do ensino fundamental}

c) Pinte dois sentimentos que você tem em relação à matemática?

d) Você acha importante aprender matemática? Por quê?

e) Para você aprender matemática é fácil ou difícil? Por quê?

f) O que você acha mais difícil e mais difícil aprender em matemática?

Na questão “a) Das disciplinas citadas abaixo enumere de 1 a 5 as matérias que mais gosta, sendo 1 a que mais gosta e 5 a que menos gosta", foram apresentadas como alternativas para os alunos, as seguintes disciplinas: Português, Matemática, História, Geografia, Ciências.

A maioria dos estudantes elencou a matemática como sendo a disciplina que mais gosta, sendo que, de 27 alunos 20 marcaram na primeira posição isso pode ser articulado ao fato dos professores, em sua maioria, mesmo com experiência negativas com a matemática sentirem prazer ao ensiná-la, conforme evidenciou-se nas entrevistas realizadas. Esse fato pode comprovar o que Chacón (2003) afirma em relação às crenças dos professores determinarem as dos estudantes. Porém, para além delas, o ensino e a aprendizagem de matemática esta envolvido em um contexto social, onde existem diversos sujeitos, pode haver então a interferência dos afetos dos pais, dos colegas, de outros grupos sociais, entre outros.

Segundo Chacón (2003) dentro do processo de socialização que ajuda formação da identidade dos sujeitos, existe o a socialização emocional que contribui para constituir a identidade emocional das pessoas, quem além de incluir a dimensão afetiva, engloba as dimensões cognitiva e comportamental. As emoções são determinadas socialmente, existem as que são considerados ideais para cada situação. Dessa forma surgem no ensino e aprendizagem de matemática e podem estar seguindo a determinação social do ato emocional quando a relação envolve os saberes matemáticos.

$\mathrm{Na}$ questão "b) Quando pensa na disciplina de matemática qual é a primeira coisa que vem a sua mente?" Nesse item do questionário buscamos descobrir quais as representações do saber matemático para os alunos. A palavra que mais apareceu foi "contas" que foi usada por 17 estudantes. Surgiram também palavras referentes a alguns conteúdos matemáticos, como divisão e fatoração, e também valores pessoais e sentimentos.

Charlot (2000) aponta que as representações do saber fazem parte de um conjunto de relações com o saber. Desse modo a relação com a matemática é um conjunto de relações

Tangram - Revista de Educação Matemática, Dourados - MS - v.2 n. 2, pp. 03 - 24 (2019) 


\section{O papel das crenças e emoções no desenvolvimento da afetividade em relação à matemática nos anos iniciais do ensino fundamental}

que o sujeito tem e que pode ser com diversos elementos que podem estar ligados a matemática, como conteúdos, pessoas, lugares, entre outros.

Nas respostas dos alunos surgiu também a emoção como uma das relações com a matemática ao serem destacadas como "coisa legal" e "felicidade" isso corrobora com as crenças e atitudes sobre a matemática e que apresenta as relações elas e tem como ingrediente o fator emocional e a afetividade. (CHACÓN, 2003).

Na questão “c) Pinte dois sentimentos que você tem em relação à matemática?”, os estudantes tinham como opções para sua escolha os seguintes sentimentos: Desespero, Felicidade, Susto, Raiva, Surpresa e Tristeza. A questão pode ser observada no quadro 1.

Quadro 1 - Questão C sobre os sentimentos em Relação â Matemática.

\begin{tabular}{|c|c|c|c|c|c|}
\hline \multicolumn{6}{|c|}{ Pinte dois sentimentos você tem em relação à matemática? } \\
\hline 0 & Feliz & $\div$ & Com raiva & $\div \%$ & Assustado \\
\hline 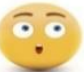 & Surpreso & $\stackrel{\circ}{\bullet}$ & Desesperado & $\Xi$ & Triste \\
\hline
\end{tabular}

Os sentimentos que mais foram marcados pelos alunos foram os positivos (feliz e surpreso), 25 alunos marcaram que se sentem felizes em relação a matemática. Dentre os seis sentimentos quatro eram negativos, e mesmo assim ficou claro que os sentimentos que prevalecem são os positivos, porém o desiquilíbrio entre sentimentos positivos e negativos aconteceu de forma não intencional. Chamou atenção os fatos de nenhum dos alunos sentir tristeza e apenas um sentir raiva em relação à disciplina, porém alguns se sentiram desesperados o que demanda um estudo mais aprofundado sobre essa emoção.

Percebeu-se nesta questão uma ênfase nas emoções negativas na proposta de sentimentos que envolvem o ensino e aprendizagem de matemática, talvez tendo por influência as experiências pessoais da pesquisadora com objeto de estudo, mas isso não foi de forma intencional. Para futuras pesquisas seria valido obter um equilíbrio entre emoções positivas e negativas, ou até mesmo compreender a construção dos conhecimentos matemáticos e a importância de emoções positivas, algo que ainda é pouco considerado na literatura sobre afetividade em matemática.

Segundo Chacón (2003) as emoções estão ligadas ao estilo matemático, a autora destaca a importância do estudo dos aspectos emocionais do conhecimento, pois ele em muitos casos pode ser a resposta dos fracassos na vida como um todo e na educação, porém não é suficiente apenas refletir sobre essas questões, é necessário que se criem propostas que

Tangram - Revista de Educação Matemática, Dourados - MS - v.2 n. 2, pp. 03 - 24 (2019) 


\section{O papel das crenças e emoções no desenvolvimento da afetividade em relação à matemática nos anos iniciais do ensino fundamental}

operem dentro da sala de aula. Acontecimentos internos ou externos desencadeiam emoções, os quais podem ter significados positivos e negativos, e quando uma expectativa do sujeito não é concretizada, surge o valor.

Na questão “d) Você acha importante aprender matemática? Por quê?”, todos os 27 alunos que responderam os questionários marcaram que é importante aprendê-la. Ao percebermos que todos os alunos marcaram que é importante aprender matemática, chegamos à conclusão, que até mesmo os alunos que assinalaram que a matemática não era sua disciplina favorita e que era difícil estavam cientes da sua importância. Condizendo com o que foi marcado na questão sobre o uso da matemática fora da escola, a maioria das justificativas para a importância do seu aprendizado está direcionada ao seu uso na vida e no cotidiano, 17 alunos justificaram a sua resposta voltados para esse aspecto da matemática, em menor número também apareceram questões relacionadas ao profissional, ao futuro, sendo que apenas uma pequena parte elencou que a ela é importante pelo aprendizado em si. Nessa questão foi possível observar ênfase na utilidade da disciplina, aprender para construir o conhecimento e para transformar não é foco, e sim a utilidade em nossa realidade cotidiana e prática.

As respostas dos alunos podem ser relacionadas às concepções e crenças dos professores, que ressaltaram o aspecto da utilidade da matemática, como se ela tivesse sendo norteada por fatores externos. Chacón (2003) afirma que a maneira como essa disciplina é apresentada aos alunos ajuda a compor as suas crenças e interferir em sua motivação, sendo que, as influências podem ser dos professores, dos livros didáticos, entre outras. A autora destaca ainda, a importância do professor não se preocupar apenas em descobrir a melhor forma de ensinar, mas sim o que realmente é a matemática. Nas respostas dos alunos podemos perceber que os professores enfatizam a utilidade da matemática e o mesmo discurso se repete nas respostas dos alunos.

Na questão “e) Para você aprender matemática é fácil ou difícil? Por quê?”. Dos 27 alunos que responderam os questionários 20 assinalaram que é fácil aprender matemática e apenas 7 que é difícil. A maioria dos alunos disse que é fácil aprender matemática, as respostas dos alunos quando justificaram elucidam que eles acreditam que quando prestam atenção nas aulas e nos professores tem mais facilidade em aprender, outra questão está relacionada ao nível de dificuldade das atividades e também o gosto pela matemática.

Tangram - Revista de Educação Matemática, Dourados - MS - v.2 n. 2, pp. 03 - 24 (2019) 


\section{O papel das crenças e emoções no desenvolvimento da afetividade em relação à matemática nos anos iniciais do ensino fundamental}

Ao mencionar o gosto da matemática é essencial trazer a sua relação com o desejo, conforme Silva (2008). O desejo é capaz de interferir na aprendizagem e na relação com o saber. O desejo não tem objeto específico, quer apenas alcançar o prazer, e pode se ligar aos certos objetos durante a vida dos sujeitos. No ensino e aprendizagem de matemática é preciso descobrir como proporcionar aos alunos ao se depararem com o objeto da matemática o desejo e por consequência o prazer na construção dos saber matemático.

Na questão “f) O que você acha mais difícil e mais difícil aprender em matemática?”, foram colocados vários conteúdos da disciplina de matemática retirados dos descritores da Prova Brasil (Brasil, 2008), para cada alternativa deveriam colocar: fácil, médio e difícil. Os conteúdos e as respostas dos alunos estão organizados no quadro 2.

Quadro 2 - Resposta para a questão F sobre as dificuldades e facilidades no aprendizado de matemática

\begin{tabular}{|l|c|c|c|}
\hline O que você acha mais difícil e mais difícil aprender em matemática? & \multicolumn{1}{c|}{ Nonteúdos $^{\mathbf{0}}$ de Alunos } \\
\hline $\begin{array}{l}\text { Identificar as figuras geométricas, compreendendo a relação entre vértice, } \\
\text { face e aresta. }\end{array}$ & 10 & 14 & 3 \\
\hline $\begin{array}{l}\text { Identificar a localização/movimentação de uma pessoa ou objeto no } \\
\text { espeço e no plano. }\end{array}$ & 8 & 16 & 3 \\
\hline $\begin{array}{l}\text { Resolver problemas envolvendo o cálculo do perímetro e da área de } \\
\text { figuras planas, desenhadas em malhas quadriculadas. }\end{array}$ & 12 & 6 & 9 \\
\hline $\begin{array}{l}\text { Resolver problemas significativos utilizando unidades de medida } \\
\text { padronizadas como km/m/cm/mm, kg/g/mg, l/ml. }\end{array}$ & 12 & 9 & 6 \\
\hline Ler e interpretar problemas matemáticos. & 15 & 8 & 4 \\
\hline Calcular e resolver as 4 operações. & 17 & 8 & 2 \\
\hline $\begin{array}{l}\text { Identificar a localização de números racionais representados na forma } \\
\text { decimal na reta numérica. }\end{array}$ & 12 & 9 & 6 \\
\hline Ler e interpretar informações e dados apresentados em gráficos e tabelas. & 14 & 10 & 3 \\
\hline $\begin{array}{l}\text { Ler Interpretação de gráfico e tabela para a identificação de características } \\
\text { previsíveis ou aleatórias de acontecimentos. }\end{array}$ & 13 & 9 & 5 \\
\hline
\end{tabular}

Fonte: Adaptado de Brasil (2008)

O que chamou a atenção nessa questão foi que em todos os conteúdos, a maioria dos alunos marcou como sendo fácil. O conteúdo que os alunos mais marcaram como sendo difícil foi "Resolver problemas envolvendo o cálculo do perímetro e da área de figuras planas, desenhadas em malhas quadriculadas." E o conteúdo que mais marcaram como sendo fácil foi "Calcular e resolver as 4 operações." Isso pode ser resultado de uma maior ênfase no ensino das quatro operações se comparado a outros conteúdos.

Observou-se nas análises das respostas tanto das professoras, quanto dos alunos, que o cotidiano escolar e as aulas de matemática estão envolvidos pela afetividade. As professoras destacaram em suas lembranças momentos ricos em afetos sendo eles negativos ou positivos, com isso fica evidente que as experiências dos sujeitos podem também 


\section{O papel das crenças e emoções no desenvolvimento da afetividade em relação à matemática nos anos iniciais do ensino fundamental}

influenciar as concepções, crenças e práticas de professores referente ao ensino e a aprendizagem de matemática.

Mesmo com vivências consideradas negativas do período de estudantes nos anos iniciais do Ensino Fundamental das professoras, os sentimentos positivos prevaleceram na relação entre elas e o saber matemático. Os alunos também destacaram em sua maioria os sentimentos positivos em relação a essa matéria e a maior parte dos alunos diz que é a disciplina que mais gosta e que é fácil de aprender. Então podemos evidenciar a possível influência dos sentimentos das professoras em relação à matemática nos dos alunos.

A maior parte dos estudantes marcou que a matemática é a disciplina que mais vai ser usada fora da escola e destacam a importância da matemática para a vida, o cotidiano, o futuro, entre outros. Esse mesmo discurso se repete na fala dos professores durante as entrevistas, estabelecendo dessa forma uma relação entre crenças das professoras e dos alunos. Tanto professoras quanto estudantes em geral, também parecem demonstrar uma visão utilitarista da matemática, destacando seu papel prático e sua necessidade para viver em sociedade, sem deixar evidente a importância do seu ensino para o desenvolvimento intelectual e para a construção de conhecimentos.

A necessidade de abordar a matemática de forma 'concreta' também é ressaltada pelas professoras. Isso se torna evidente no destaque das professoras para a influência das metodologias usadas durante a aula de matemática e a importância da relação entre teoria e prática durante a formação inicial. Quando se falou em dificuldade e facilidade de ensinar matemática foi possível observar que os docentes se dividem entre os que acham a matemática a mais difícil de ensinar e os que consideram a mais fácil, não havendo visões intermediárias sobre esse aspecto.

\section{Considerações finais}

A pesquisa teve um resultado diferente do esperado no que se refere às relações afetivas que os alunos estabelecem com o saber matemático. O início dos estudos foi motivado pelo discurso de muitos sujeitos enfatizando emoções e crenças ligadas às experiências negativas com a matemática na escola. Porém durante o processo de analise e reflexão dos dados obtidos foi possível perceber que os alunos têm em geral uma visão

Tangram - Revista de Educação Matemática, Dourados - MS - v.2 n. 2, pp. 03 - 24 (2019) 


\section{O papel das crenças e emoções no desenvolvimento da afetividade em relação à matemática nos anos iniciais do ensino fundamental}

positiva sobre o ensino e aprendizagem de matemática e que a consideram essencial em suas vidas.

Foi possível identificar alguns fatores que influenciam a mobilização dos professores e alunos para o ensino e aprendizagem de matemática. A partir dos estudos e análise dos dados obtidos com as entrevistas e questionários, tornou-se evidente que os fatores referentes à afetividade são decisivos no ensino e aprendizagem de matemática e que as relações estabelecidas entre os sujeitos e o saber matemático estão carregadas de afetividade, mesmo que isso seja pouco percebido pelos sujeitos envolvidos.

O conceito de domínio afetivo adotado nesse trabalho engloba além de emoções, sentimentos, atitudes e considerações, inclui também as crenças e concepções dos sujeitos. Com a discussão e articulação dos dados das professoras e alunos foi possível perceber e evidenciar que as crenças e concepções dos professores influenciam significativamente nas crenças dos estudantes. Porém, outros fatores externos à escola também ajudam a compor as crenças dos alunos sobre a matemática e não podemos responsabilizar apenas os professores pelo sentido, desejo e gosto que os alunos têm por ela. Chacón (2003) divide as crenças entre as relacionadas à matemática como disciplina e as dos alunos e professores sobre si mesmos e a relação que estabelecem com a matemática. As primeiras possuem um predomínio menor do componente afetivo, diferente da segunda que está mais ligada à afetividade.

As emoções e sentimentos das professoras também podem estar influenciando as emoções e sentimentos dos estudantes, quando comparadas às respostas dos alunos e das professoras, ficaram evidentes os sentimentos e emoções positivas referentes à matemática, e isso pode ser ocasionado pelo caráter epidêmico (LA TAILLE, OLIVEIRA, DANTAS 2016) da emoção que é uma característica social da emoção. As emoções são universais e estão expressas nos alunos, e as mesmas expressões que acontecem no oriente podem ser identificadas no ocidente. A afetividade está presente nos seres humanos por toda sua vida e a partir do afetivo que são desencadeadas as atitudes que envolvem também o valor que os sujeitos dão à matemática.

Ao analisarmos os dados de estudantes e das professoras ficaram evidentes algumas possíveis relações entre suas concepções, crenças e sentimentos sobre o ensino e aprendizagem de matemática. Porém cabe aqui destacar que os professores não são únicos que contribuem para relação que os estudantes estabelecem com os conhecimentos matemáticos, o contexto social, cultural e econômico do qual os sujeitos fazem parte tem um

Tangram - Revista de Educação Matemática, Dourados - MS - v.2 n. 2, pp. 03 - 24 (2019) 


\section{O papel das crenças e emoções no desenvolvimento da afetividade em relação à matemática nos anos iniciais do ensino fundamental}

papel determinante, podendo ter interferência da família, da mídia, materiais didáticos, entre outros.

\section{Referências}

ALVES, J. A. A; DANTAS, V. A. O; OLIVEIRA, M. S. (2012) Influências afetivas no ensino- aprendizagem de matemática. $6^{\circ}$ Colóquio Internacional: Educação e Contemporaneidade. São Cristovão-SE/Brasil. 20 a 22 de setembro. pp. 1-12.

BRASIL. Ministério da Educação. (2008) PDE: Plano de Desenvolvimento da Educação: Prova Brasil: ensino fundamental: matrizes de referência, tópicos e descritores. Brasília: MEC, SEB; Inep.

CHACÓN, I. M. G. (2003) Matemática emocional: os afetos na aprendizagem de matemática. Trad. Daisy Vaz de Moraes. Porto Alegre: Artmed.

CHARLOT, B. (2000) Da relação com o saber: elementos para uma teoria. Porto Alegre: Artes Médicas Sul.

KISHIMOTO, T. M. (1998). Bruner e a brincadeira. In: T. M. KISHIMOTO. (Org.). et.al. O brincar e suas teorias. (1.ed. pp. 139-153.) São Paulo: Cencage Learning.

LA TAILlE, Y; OLIVEIRA, M. K; DANTAS, H. (2016) Piaget, Vygotsky, Wallon: teorias psicogenéticas em discussão. 27a ed. São Paulo: Summus.

MOURA, A. R. L; PALMA, R. C. D. (2009) O material didático no ensino de matemática: lembranças deixadas em alunos de Pedagogia. Série-Estudos - Periódico do Mestrado em Educação da UCDB. Campo Grande - MS. n.28, julho/dezembro. pp. 135-150.

PONTE, J. P. (1992) Concepções dos professores de Matemática e processos de formação. In: BROWN, M.; FERNANDES, D.; MATOS, J. F.; PONTE, J. P. (Orgs.). Educação matemática: temas de investigação. (pp. 1-40) Lisboa: Instituto de Inovação Educacional.

SILVA, V. A. (2008) Relação com o saber na aprendizagem matemática: uma contribuição para a reflexão didática sobre as práticas educativas. Universidade Federal de Sergipe, Departamento de Educação e Núcleo de Pós-Graduação em Educação Grupo de Pesquisa Educação e Contemporaneidade. Revista Brasileira de Educação. v. 13, n. 37, janeiro/abril. pp. 150-190.

Tangram - Revista de Educação Matemática, Dourados - MS - v.2 n. 2, pp. 03 - 24 (2019) 


\section{O papel das crenças e emoções no desenvolvimento da afetividade em relação à}

matemática nos anos iniciais do ensino fundamental

SILVEIRA, M. R. A. (2002) "Matemática é difícil": um sentido pré-construído evidenciado na voz do aluno. Associação Nacional de Pós-Graduação e Pesquisa em Educação, 2002, Caxambu. Anais... ANPED, 2002. Disponível em: <http://www.ufrrj.br/emanped/paginas/conteudo_producoes/docs_25/matematica.p df.> Acesso em 08 de agosto 2017. pp. 1-17.

Enviado:11/06/2018

Aceito: $10 / 11 / 2018$

Tangram - Revista de Educação Matemática, Dourados - MS - v.2 n. 2, pp. 03 - 24 (2019) 